\title{
Relationship between Turbulence and Drizzle in Continental and Marine Low Stratiform Clouds
}

\author{
PALOMA BORQUE \\ Department of Atmospheric and Oceanic Sciences, McGill University, Montreal, Quebec, Canada, and Department of Atmospheric \\ Sciences, University of Illinois at Urbana-Champaign, Urbana, Illinois \\ EDWARD P. LUKE \\ Brookhaven National Laboratory, Upton, New York \\ PAVLOS KOLLIAS \\ Department of Atmospheric and Oceanic Sciences, McGill University, Montreal, Quebec, Canada, and Brookhaven \\ National Laboratory, Upton, New York, and School of Marine and Atmospheric Sciences, Stony Brook University, \\ State University of New York, Stony Brook, New York \\ FAN YANG \\ Brookhaven National Laboratory, Upton, New York
}

(Manuscript received 23 February 2018, in final form 30 July 2018)

\begin{abstract}
Turbulence and drizzle-rate measurements from a large dataset of marine and continental low stratiform clouds are presented. Turbulence peaks at cloud base over land and near cloud top over the ocean. For both regions, eddy dissipation rate values of $10^{-5}-10^{-2} \mathrm{~m}^{2} \mathrm{~s}^{-3}$ are observed. Surface-based measurements of cloud condensation nuclei number concentration $N_{\mathrm{CCN}}$ and liquid water path (LWP) are used to estimate the precipitation susceptibility $S_{0}$. Results show that positive $S_{0}$ values are found at low turbulence, consistent with the principle that aerosols suppress precipitation formation, whereas $S_{0}$ is smaller, and can be negative, in a more turbulent environment. Under similar macrophysical conditions, especially for medium to high LWP, high (low) turbulence is likely to lessen (promote) the suppression effect of high $N_{\mathrm{CCN}}$ on precipitation. Overall, the turbulent effect on $S_{0}$ is stronger in continental than marine stratiform clouds. These observational findings are consistent with recent analytical prediction for a turbulence-broadening effect on cloud droplet size distribution.
\end{abstract}

\section{Introduction}

Turbulence is always present in clouds. Several mechanisms have been proposed that link turbulence to cloud evolution and microphysics. Small-scale turbulence influences the spatial distribution of particles having nonnegligible inertia, causing spatial inhomogeneities and regions of preferential drop concentration (e.g., Eaton and Fessler 1994; Vaillancourt et al. 2002). This causes faster growth by condensation in regions of low concentration, leading to a broadening of the drop size spectrum. Turbulence also modifies collection efficiencies.

\footnotetext{
Corresponding author: Paloma Borque, paloma@illinois.edu
}

Because of their finite inertia, the relative velocities of particles in a turbulent flow are not equal to their terminal velocities. This causes fluctuations in droplet fall speeds and horizontal motions that increase growth by collection (Pruppacher and Klett 2010). As turbulence is also likely to modify the flow fields around the droplets, droplet collision efficiencies in a turbulent flow are expected to be greater than in a laminar flow (e.g., Pinsky et al. 2006, 2008; Khain et al. 2007; Franklin et al. 2007; Ayala et al. 2008; Wang et al. 2008). Furthermore, turbulence can drive supersaturation fluctuations and thus affect the condensational growth of cloud droplets (e.g., Cooper 1989; Khvorostyanov and Curry 1999). In addition, turbulence-induced mixing and entrainment can 
also modify cloud droplet size distribution by evaporation and activation of cloud droplets (e.g., Khain et al. 2000; Yang et al. 2016; Grabowski et al. 2018).

Most previous observational studies (e.g., Albrecht 1989; Baker 1993; Terai et al. 2012; Mann et al. 2014; Hudson and Noble 2014; Jung et al. 2016) and modeling efforts (e.g., Nicholls 1987; Austin et al. 1995; Delobbe and Gallée 1998; Feingold et al. 2013) of marine shallow clouds have focused on the effect that cloud condensation nuclei number concentration has on precipitation production in stratiform clouds. Feingold et al. (1999) used surface-based observations to investigate the role of cloud dynamics in cloud droplet number concentration and drizzle formation. However, their study was hindered by its limited dataset and its poor temporal resolution. Recently, Chandrakar et al. (2016) found that both the standard deviation of the cloud droplet size distribution and cloud droplet size dispersion (standard deviation normalized by the mean) increase with a decrease of aerosol concentrations. The spectrum broadening observed under different aerosol conditions shows excellent agreement with an analytical equation, suggesting that turbulence can enhance supersaturation fluctuation, broaden the drop size spectrum, and thus favor initial drizzle formation. Although this analytical solution shows the connection of drop size spectrum to both aerosol and turbulence properties, only the effect of aerosol on cloud droplet size distribution was verified with a constant turbulent environment, while the effect of turbulence has not been investigated. However, it should be mentioned that results from Chandrakar et al. (2016) are based on laboratory experiments where the clouds in a convection chamber reach a steady state and the sink of cloud droplets is sedimentation, rather than evaporation, autoconversion, or accretion. It is not clear to what extent the clouds in the chamber can represent atmospheric clouds. In addition, previous studies also show the opposite trends: the width of cloud droplet size distribution increases with the increase of aerosol number concentration. For example, Liu et al. (2006) derived an analytical expression for cloud droplet size dispersion showing that dispersion increases with aerosol loading; this result has been supported by observations in stratocumulus clouds (Martin et al. 1994). Thus, the effect of turbulence on drizzle formation remains a challenge that requires further analysis from both simulated and real clouds.

In this study, profiles of eddy dissipation rate $\varepsilon$ are retrieved for a large dataset of low stratiform clouds using Doppler velocity time series observations from profiling Doppler cloud radars. Borque et al. (2016) showed that following Kolmogorov's theory (Kolmogorov 1941), it is possible to determine the eddy dissipation rate from millimeter Doppler radars even at times when drizzling particles are present in the radar volume.

\section{Data and methods}

This study focuses on days having low-level stratiform clouds with and without drizzle present. For these days, the following variables are available. Cloud condensation nuclei number concentration $N_{\mathrm{CCN}}\left(\mathrm{cm}^{-3}\right)$ is estimated at the surface from a Drop Measurement Technologies CCN counter (Hageman et al. 1996) at $0.55 \%$ supersaturation (Roberts and Nenes 2005). Liquid water path (LWP; $\mathrm{g} \mathrm{m}^{-2}$ ) measurements are obtained from the twochannel microwave radiometer (Gaustad and Riihimaki 1996). Rain rates $R\left(\mathrm{~mm} \mathrm{day}^{-1}\right)$ are estimated $140 \mathrm{~m}$ below cloud base (two range gates) using combined radar and lidar observations following the O'Connor et al. (2005) methodology. It has been demonstrated that W-band cloud radar (WACR; Hardin et al. 1990) reflectivity suffered from a low bias of about $8 \mathrm{~dB} Z$ during its entire deployment at the Azores, for which we have compensated the data used in this study. Cloud-top heights are determined from the maximum height of the power return from the WACR once the observations are noise filtered following the procedure shown in Kollias et al. (2014). Cloud-base heights are determined from the column maximum vertical gradient in the collocated laser ceilometer backscatter. Eddy dissipation rates $\varepsilon\left(\mathrm{m}^{2} \mathrm{~s}^{-3}\right)$ are estimated from the WACR Doppler velocity measurements for a 100-point window (representing $\sim 7$-min average) following the methodology shown in Borque et al. (2016). For consistency, this 7-min-average window is applied to all the variables analyzed herein.

Observations presented here correspond to two U.S. Department of Energy (DOE) Atmospheric Radiation Measurement (ARM) Mobile Facility (AMF) deployments (Mather and Voyles 2013). This dataset consists of 18 days of shallow stratiform cloud observations collected from August 2009 through November 2010 at Graciosa Island, Azores (GRW site; Wood et al. 2015) and 14 days of observations collected in September and October 2007 at Black Forest, Germany (FKB site; Wulfmeyer et al. 2008). All the observations analyzed in this study correspond to warm-phase-only low-level stratiform clouds. The determination of the warm-phase-only microphysics is done using clouds with cloud-top temperature greater than $0^{\circ} \mathrm{C}$. The determination of the stratiform clouds is based on visual inspection of the radar observations and the requirement for $80 \%$ or higher hourly cloud fraction. These observations represent the largest dataset used for this type of analysis to date, with over $300 \mathrm{~h}$ of observations from each location, presenting a unique opportunity to study the dynamical and microphysical structure of shallow clouds 

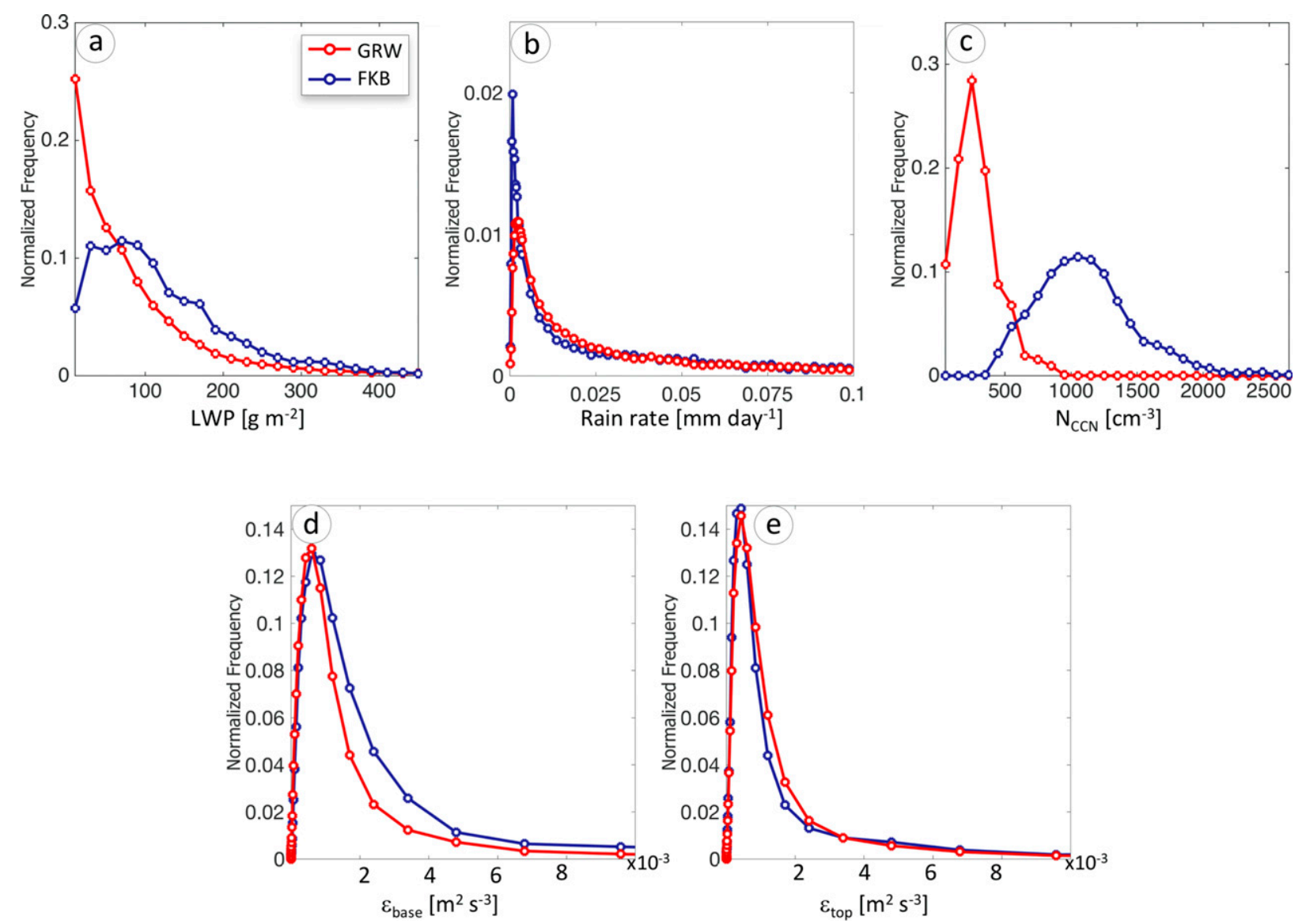

FIG. 1. Normalized histograms of (a) LWP; (b) rain rate; (c) $N_{\mathrm{CCN}}$; and (d),(e) mean $\varepsilon$ at cloud base and cloud top, respectively, at Graciosa Island (red) and Black Forest (blue) ARM sites.

in marine (GRW site) and continental (FKB site) environments with statistically robust information.

Comparing the overall characteristics of the marine and continental stratiform clouds shows that marine stratiform clouds (GRW) have a higher mean rain rate $\left(9.73 \times 10^{-2} \mathrm{~mm} \mathrm{day}^{-1}\right)$ than their continental counterparts (FKB; $6.81 \times 10^{-2} \mathrm{~mm} \mathrm{day}^{-1}$ ) (Fig. 1b). This is in connection with a much lower cloud condensation nuclei number concentration present at the marine site (Fig. 1c) even though the liquid water path is lower than at the continental site (Fig. 1a). This is consistent with the second aerosol indirect effect (Albrecht 1989) and the role of aerosols in rain suppression. Continental clouds are also mostly characterized by stronger cloud-base turbulence and lower cloud-top turbulence than marine clouds (Figs. 1e and 1f). The overall characteristics of the observations collected at both sites are shown in Fig. 2.

\section{Cloud turbulence}

The large dataset of turbulence measurements provides the opportunity to study the statistical properties of turbulence at the previously described contrasting locations. The vertical structure of eddy dissipation rate has some clear differences between continental and marine stratiform clouds (Fig. 3). Turbulence is maximum at cloud base and then steadily decreases toward cloud top in the continental environment (Fig. 3a). On the other hand, marine clouds tend to be the least turbulent at cloud base (Fig. 3b). On average, turbulence at GRW increases from cloud base to just above midcloud and then sharply decreases at cloud top. Overall, clouds at FKB are more turbulent (mean $\varepsilon=7.88 \times 10^{-4} \mathrm{~m}^{2} \mathrm{~s}^{-3}$ ) than at GRW (mean $\varepsilon=6.68 \times 10^{-4} \mathrm{~m}^{2} \mathrm{~s}^{-3}$ ). This mostly corresponds to a much more turbulent cloud base at FKB (mean $\varepsilon=1.15 \times 10^{-3} \mathrm{~m}^{2} \mathrm{~s}^{-3}$ ) than at GRW (mean $\varepsilon=6.62 \times$ $10^{-4} \mathrm{~m}^{2} \mathrm{~s}^{-3}$ ). There is a distinct time-dependent behavior at both locations analyzed. On average, clouds are likely to be more turbulent around 0600 UTC (0800 LT; $\varepsilon=5.09 \times$ $\left.10^{-4} \mathrm{~m}^{2} \mathrm{~s}^{-3}\right)$ and the least turbulent around $1800 \mathrm{UTC}$ $\left(2000 \mathrm{LT} ; \varepsilon=3.91 \times 10^{-4} \mathrm{~m}^{2} \mathrm{~s}^{-3}\right)$ over the continental site. When considering the marine site, there is a 4-h shift in the diurnal cycle of turbulence, and thus clouds are more likely to be more turbulent around midnight 


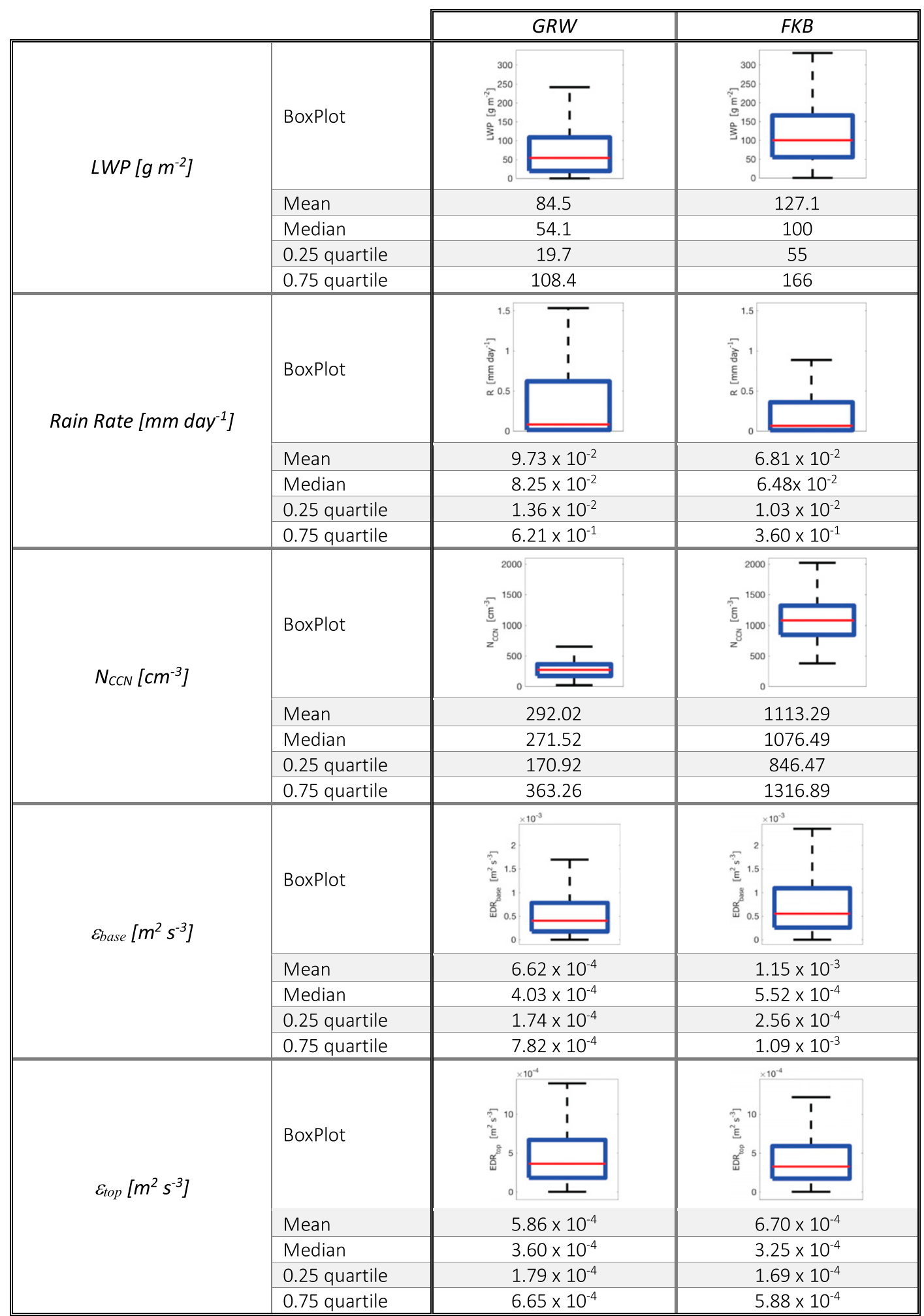

FIG. 2. Mean, median, $25 \%$, and $75 \%$ quartiles of (top to bottom) LWC, rain rate, $N_{\mathrm{CCN}}, \varepsilon_{\text {base }}$, and $\varepsilon_{\text {top }}$ for GRW and FKB sites. The boxplot of each variable is also included. 

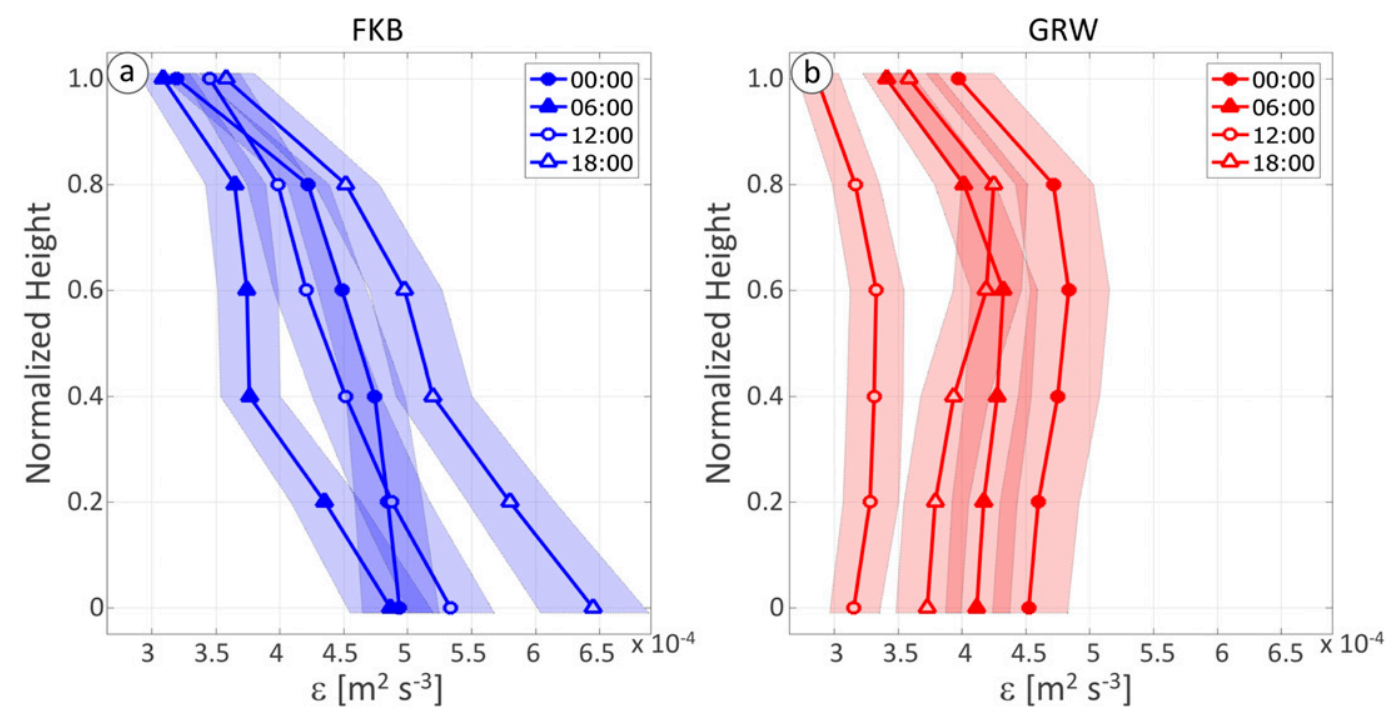

FIG. 3. Vertical profiles of eddy dissipation rate averaged every $6 \mathrm{~h}$ around the times (UTC) noted in the legend at (a) Black Forest and (b) Graciosa Island ARM sites. The height of all observed clouds was normalized between 0 for cloud base and 1 for cloud top. The shaded region represents plus and minus one standard deviation around the mean profile.

$\left(0000 \mathrm{UTC} / \mathrm{LT} ; \varepsilon=4.57 \times 10^{-4} \mathrm{~m}^{2} \mathrm{~s}^{-3}\right)$ and less turbulent around noon $(1200 \mathrm{UTC} / \mathrm{LT} ; \varepsilon=3.19 \times$ $\left.10^{-4} \mathrm{~m}^{2} \mathrm{~s}^{-3}\right)$. This time-dependent behavior of turbulence is consistent at both sites throughout the entire cloud layer.

The higher low-level turbulence observed at the FKB site shows the strong dependence of these clouds on surface conditions, whereas the highest turbulence being observed near cloud top at the GRW site is consistent with these clouds being mostly driven by cloud-top thermodynamics, in particular with the expected effect of cloud-top radiative cooling, in the marine regime. The diurnal variability of $\varepsilon$ is consistent with the timing of the turbulence-generating mechanisms. Over land there is a distinct increase in turbulence intensity in the afternoon hours, in connection with a surface-driven boundary layer. On the other hand, marine clouds tend to be more turbulent at night, likely in response to a stronger cloudtop radiative cooling in comparison to the daytime, when the absorption of solar radiation reduces the cooling magnitude (Fig. 3).

\section{Precipitation susceptibility and the impact of turbulence}

Observations analyzed in this work provide a unique opportunity to investigate aerosol-cloud-turbulence interactions in continental and marine stratiform clouds. Precipitation susceptibility $S_{0}$ was first introduced by Feingold and Siebert (2009) and has been used since to provide a quantitative measure of the influence of aerosols on precipitation (e.g., Feingold and Siebert 2009; Terai et al. 2012; Mann et al. 2014; Jung et al. 2016). It is expressed as

$$
S_{0}=-\frac{d \ln (R)}{d \ln \left(N_{\mathrm{CCN}}\right)}
$$

where $R$ is the rain rate estimated at about $140 \mathrm{~m}$ below cloud base and $N_{\mathrm{CCN}}$ is the cloud condensation nuclei number concentration measured at the surface. More specifically, it is the susceptibility of drizzle intensity (e.g., $S_{I}$ in Terai et al. 2012), as nondrizzling cloud segments are excluded from our analysis. It is important to isolate the role of aerosols from any macrophysical properties (such as liquid water path or cloud thickness) that may have an impact on drizzle inhibition and/or formation. For this, as in previous studies (e.g., Terai et al. 2012), $S_{0}$ is calculated for each quartile of LWP in an effort to exclude the effect of the macrophysical properties. Therefore, the edges of each LWP interval are different for both sites analyzed here (Fig. 4). Furthermore, $S_{0}$ is computed using the tercile logdifferencing approach as defined by Terai et al. (2012) and the uncertainty for each interval is calculated using bootstrap resampling. Different values of supersaturation were used to estimate $N_{\mathrm{CCN}}$ showing no marked impact in the estimated susceptibility as a function of supersaturation used.

For shallow marine and continental clouds, precipitation susceptibility is positive for almost every liquid water path interval considered (Fig. 4). This is consistent 

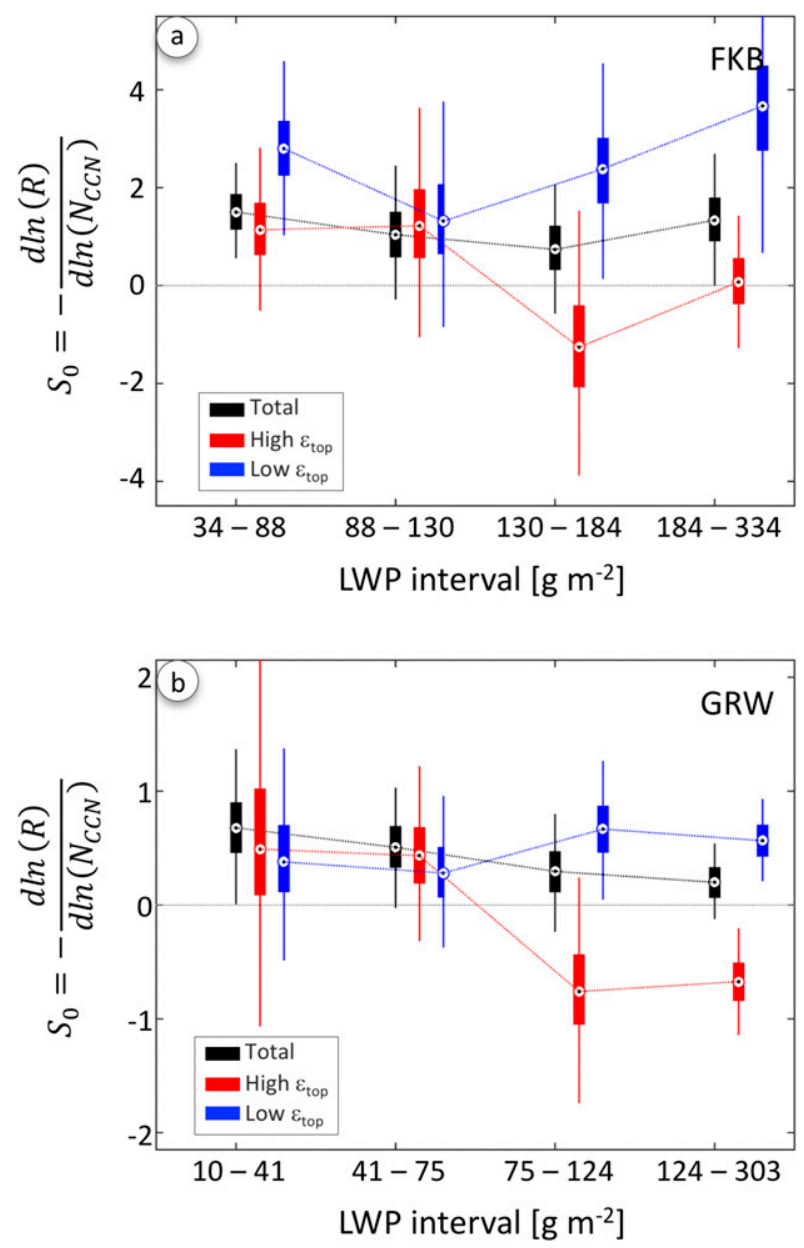

FIG. 4. Plots of $S_{0}$ computed for the full datasets (black) and for low and high turbulence at cloud top (blue and red, respectively). The bottom and top quartiles of eddy dissipation rate shown in Fig. 2 were used to subset the data into low- and high-turbulence datasets at each site. Precipitation susceptibility is computed for equally weighted LWP intervals for the (a) FKB and (b) GRW ARM sites. For each plot, the tops and bottoms of each box represent the 25th and 75 th percentiles of the samples, respectively. The white circle in each box is the sample median. The whiskers (lines extending above and below each box) represent the ends of the interquartile ranges to the farthest observations within the LWP interval.

with previous studies, suggesting an inverse relationship between rain rate and cloud condensation nuclei number concentration (e.g., Albrecht 1989). For shallow marine clouds, $S_{0}$ tends to monotonically decrease for increasing LWP values (Fig. 4b). This is also consistent with previous studies (Terai et al. 2012; Mann et al. 2014), indicating a less important role of $N_{\mathrm{CCN}}$ in determining precipitation behavior for higher values of LWP. This is likely in association with the evolution of the dominant cloud processes from autoconversion, where $N_{\mathrm{CCN}}$ has a large impact on rain-rate production, to accretion, where $N_{\mathrm{CCN}}$ is inconsequential to drizzle formation (Feingold et al. 2013). However, this behavior does not seem to correlate well for the continental case, where for the highest values of LWP analyzed, $S_{0}$ has a positive trend with respect to LWP (Fig. 4a). It can also be seen that the magnitude of $S_{0}$ at FKB is larger than that at GRW. This is consistent with Feingold et al. (2013), who showed via a variety of simulations that $S_{0}$ for an environment with high $N_{\mathrm{CCN}}$ is expected to be larger than for a less polluted environment.

The present study goes beyond previous ones by examining the connection between turbulence and the precipitation susceptibility parameter. For each LWP interval, $S_{0}$ is calculated for relatively high- and lowturbulence conditions, as defined by the top and bottom quartiles of eddy dissipation-rate $(\varepsilon)$ estimates. Overall, the largest impact of turbulence on $S_{0}$ occurs for the higher LWP intervals where precipitation susceptibility is lower (higher) when the dataset is sampled for a more (less) turbulent environment (Fig. 4). This suggests that stronger turbulence is associated with smaller $S_{0}$ and a smaller role of $N_{\mathrm{CCN}}$ in precipitation suppression. This effect of turbulence on $S_{0}$ is stronger for continental clouds compared with marine clouds. These findings are consistent with the analytical expression of the turbulence broadening effect on cloud droplet size distribution derived in Chandrakar et al. (2016). Based on Eq. (5) in Chandrakar et al. (2016), the width of the droplet size distribution is proportional to $\tau_{s}^{2} / \tau_{t}$, where $\tau_{s}$ is the system response time and $\tau_{t}$ is the turbulence correlation time. It is expected that stronger turbulence with smaller $\tau_{t}$ will broaden the droplet size distribution, enhance drizzle formation, counteract the aerosol effect on precipitation, and thus lead to smaller $S_{0}$. Results from the two sites analyzed here show a general agreement with this prediction: $S_{0}$ in a turbulent environment is smaller than in a less turbulent environment. In addition, $\tau_{s}$ will decrease with the increase of turbulence strength in relatively clean clouds (e.g., marine clouds), but it is almost independent of the turbulence for relatively polluted clouds (e.g., continental clouds). Therefore, it is expected that turbulence has a stronger effect on cloud droplet size distribution in relatively polluted clouds. This can explain why the effect of turbulence on $S_{0}$ is larger for continental than marine stratiform clouds as shown in Fig. 4. However, it is interesting to note that $S_{0}$ is negative at high LWP and high turbulent levels, suggesting that the increase of aerosol concentration will enhance rather than suppress rain rate in a stronger turbulence environment. This phenomenon might be related to other mechanisms worthy of future investigation. A caveat of Chandrakar et al. (2016) is that their analysis considers only the broadening of the droplet 
spectrum because of condensational growth (no collision) in a turbulent environment. Several studies have shown that higher turbulence (higher $\varepsilon$ ) enhances the collection kernel, promoting rain formation, and that the importance of collision-coalescence increases with LWP (e.g., Wang et al. 2008). This mechanism can enhance the turbulence effect on $S_{0}$ for both marine and continental clouds at high LWP values, which can explain the more evident separation for the highest two quartiles of liquid water path intervals (Fig. 4). Moreover, turbulence does not seem to have an important role in precipitation susceptibility, especially for marine clouds, at low LWP values (Fig. 4b). A possible reason for this behavior is that stronger turbulence might decrease the droplet residence time by transporting droplets to downdraft regions and moving them below the cloud base faster or, for relatively thin clouds, by dissipating them more quickly.

\section{Rain-rate dependence on macroscopic variables}

To examine the influence of cloud depth and drop concentration on local drizzle rates, previous studies have related drizzle rate from marine stratiform clouds to cloud thickness and drop concentration from either remotely sensed estimates or in situ observations (Pawlowska and Brenguier 2003 for the Second Aerosol Characterization Experiment (ACE-2; Comstock et al. 2004; Wood 2005 for EPIC; van Zanten et al. 2005 for DYCOMS II observations). This work expands these analyses to groundbased observations collected at the GRW and FKB sites, thus providing another source of information for marine clouds and further enhancing the analyses by including observations from a continental environment.

The results presented here are in qualitative agreement with those found in previous studies, thus supporting a near-cubic dependence of rain rate on cloud depth and an inverse dependence on cloud droplet concentration (Fig. 5). It is expected that the observations from the GRW site would most closely resemble the behavior found in previous studies given their marine nature. However, observations at the FKB site also show good agreement with those from previous field campaigns, thus suggesting that continental shallow clouds are expected to scale with the mean cloud thickness and cloud droplet concentration in a similar manner (Figs. 5a and 5d).

Given the nature of the observations analyzed here, the connection between rain rate, cloud thickness $H$, and cloud condensation nuclei number concentration is extended toward lower values of rain rate. This seems to lead to a steeper relation between $R$ and $H^{3} N_{\mathrm{CCN}}^{-1}$ than that expected when analyzing rain-rate values above
$10^{-1} \mathrm{~mm} \mathrm{day}^{-1}$. This characteristic is also a consequence of the narrow distribution that $H^{3} N_{\mathrm{CCN}}^{-1}$ has in the cases analyzed here (figure not shown). It is interesting to note that continental clouds produce a very similar slope for the contours of high joint frequency of occurrence to the marine case but with an expected lower rain rate (Figs. 5a and 5d).

Most importantly, this work expands on the previously mentioned studies by adding the effects of eddy dissipation rate at cloud top and cloud base. Continental clouds exhibit a different behavior for rain rate, cloud thickness, and cloud condensation nuclei number concentration depending on the intensity of turbulence and its location in the cloud (Figs. 5a-c; Figs. 5e and 5f).

The highest value of the normalized joint frequency tends to be associated with high turbulence at cloud base and low turbulence at cloud top (Figs. 5b and 5f). Similarly, precipitation intensity is expected to decrease for the lowest values of $\varepsilon$ at cloud base and the highest values of $\varepsilon$ at cloud top (Figs. 5c and 5e). These observed differences at the FKB site when analyzing the different states of turbulence further suggest a connection with surface dynamics. In the case of marine clouds, as one would expect from the previously discussed vertical structure of turbulence, there is no significant change in the interdependence of rain rate, cloud thickness, and $N_{\mathrm{CCN}}$ based on the cloud level where $\varepsilon$ is estimated (figure not shown). These results demonstrate how sensitive rain rate is to cloud depth, drop concentration, and turbulence and further emphasize the importance of understanding turbulence the in-cloud vertical structure and its impacts on continental clouds.

\section{Summary and conclusions}

This study presents the largest dataset known to the authors of radar-based measurements of turbulence in low stratiform clouds from two contrasting sites. The goals of this study are to (i) provide a statistical description of in-cloud turbulence at these locations and (ii) investigate the role of turbulence in precipitation formation and/or inhibition in low stratiform clouds. Data from two AMF deployments, one at Graciosa Island (GRW) and the other at the Black Forest (FKB) are analyzed. This large observational dataset enables statistically robust results for shallow clouds in marine (GRW) and continental (FKB) environments. The overall characteristics of this dataset show that precipitation rates observed at FKB are less (despite having consistently higher liquid water path values) than at GRW. This result is most likely an indication of the secondary aerosol indirect effect with aerosols suppressing rain-rate formation at the FKB site. 

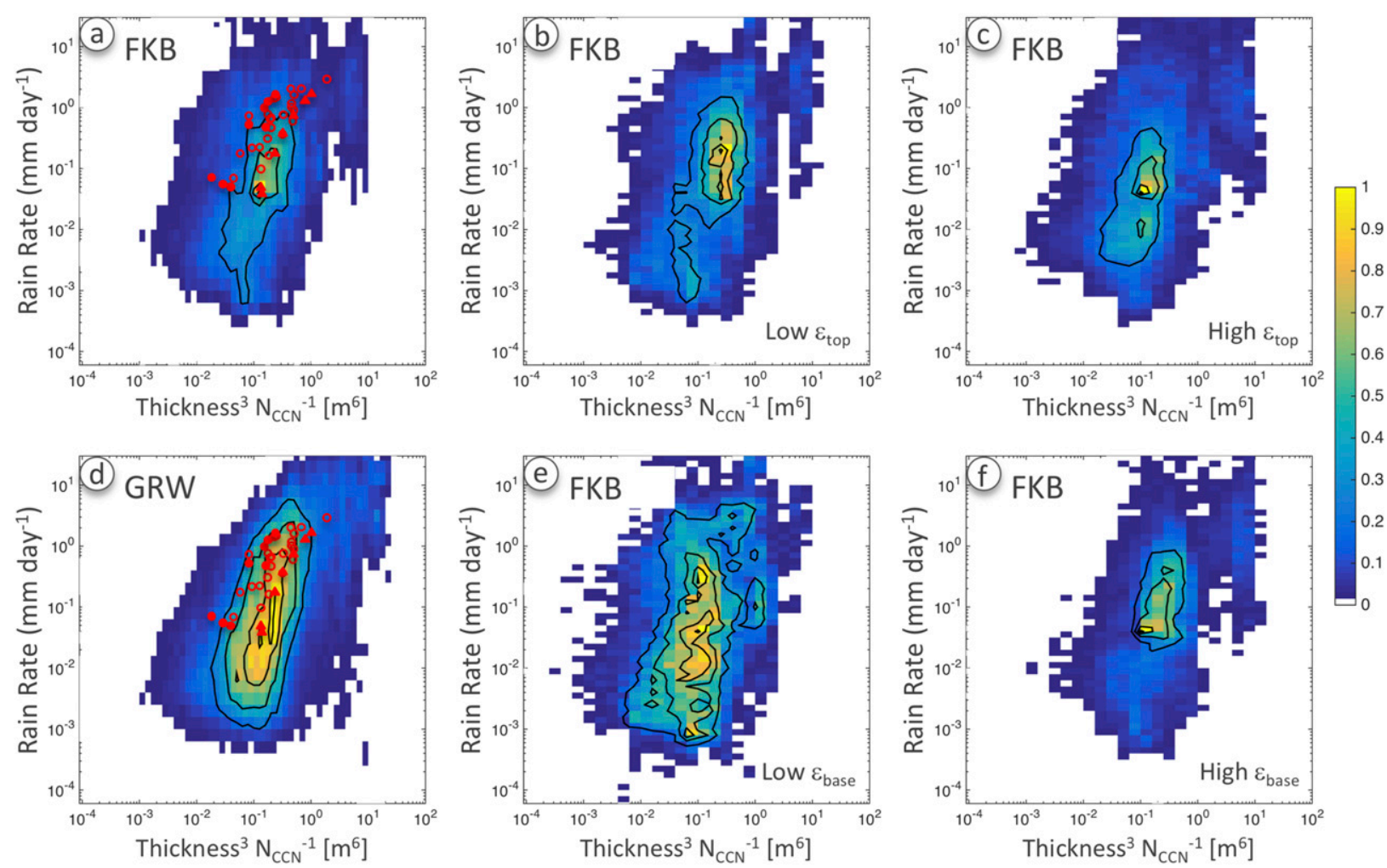

FIG. 5. (left) Normalized joint frequency of occurrence of rain rate vs $H^{3} N_{\mathrm{CCN}}^{-1}$ at (a) Black Forest and (d) Graciosa Island ARM sites. The Black Forest dataset is further separated into cases with (b),(e) low turbulence and (c),(f) high turbulence at (b),(c) cloud top and (e),(f) cloud base. The bottom and top quartiles of eddy dissipation rate at each cloud height, shown in Fig. 2, were used to subset the data into low- and high-turbulence datasets at each site. The black contours represent the joint frequency of occurrence equal to $0.25,0.5,0.75$, and 0.9, and the different markers present in (a) and (d) represent observations from previous field campaigns (Pawlowska and Brenguier 2003: red filled circle; van Zanten et al. 2005: red triangle; Comstock et al. 2004: red circle). Note that these experimental values were obtained from Fig. 21.2 of Brenguier and Wood (2009).

Regarding the vertical structure of turbulence, the averaged profiles of eddy dissipation rate at GRW exhibit their maxima at nighttime near the cloud top, consistent with a top-driven boundary layer, whereas the highest values of turbulence occur in the afternoon and in the lower part of the cloud for FKB, consistent with a surface-driven boundary layer. This vertical structure of turbulence seems to influence the formation and/or inhibition of precipitation from shallow continental clouds, where higher (lower) rain rates at FKB are likely to be associated with high (low) turbulence at cloud base and (high) low turbulence at cloud top. On the other hand, marine stratiform cloud, represented by the observations at the GRW site, does not show a noticeable dependence of rain rate on the vertical profile of turbulence at the GRW site.

Precipitation susceptibility $S_{0}$ was used to quantify the influence of aerosols on precipitation. It was found that for both continental and marine environments, $S_{0}$ is positive, consistent with aerosols suppressing precipitation formation. Over the marine environment, $S_{0}$ tends to monotonically decrease for increasing liquid water path, confirming previous authors' suggestions of a transition between the effects of droplets growing by autoconversion and those growing by accretion. This trend, however, is less clear at the continental site. The main contribution of this work is the inclusion of the role of turbulence in $S_{0}$. The results presented in section 4 show that for medium to high values of liquid water path, low turbulence at cloud top is likely to promote the effect of cloud condensation nuclei number concentration in precipitation suppression, whereas high turbulence is likely to counteract this effect. This suggests that turbulence can broaden droplet size distribution by either condensational growth or collisional growth, thus benefiting drizzle formation and hence decreasing the aerosol influence on precipitation. On the other hand, turbulence does not seem to play an important role in precipitation inhibition or formation for low values of liquid water path (lowest two quartiles). 
It should be noted that besides the microscale turbulent effects on collision-coalescence, the existence of small-scale recirculating turbulent eddies could lead to greater accretion growth rates and the resultant broadening of the droplet size distribution (e.g., Nicholls 1987; Baker 1993; Austin et al. 1995; Korolev et al. 2013). Disentangling which process is dominant in these clouds is not possible with the observations analyzed in this work, but it can be further explored using large-eddy simulations (LES). This modeling effort could not only test which is the dominant process leading to the generation of drizzle but also clarify correlation and causation between aerosols, turbulence, and drizzle initiation.

The results presented in this work show the importance of turbulence in cloud evolution. Turbulence acts in a different manner for marine and continental stratiform clouds, and needs to be taken into consideration when analyzing cloud microphysical processes leading to drizzle formation (and inhibition). It can also be of interest in the analysis of the effects that different mechanisms have at the different stages of cloud evolution, for example, whether turbulence is expected to act differently at the initiation versus the decay stage. Unfortunately, this was not possible in the present work given the nature of the dataset used, as different stages of the cloud life cycle cannot be distinguished using profiling radars' observations alone and a more synergetic approach is needed. Therefore, it should be of interest for future work to add extra sources of information, for example, from a radar scanning in plan position indicator mode or from cloud-tracking algorithms (Borque et al. 2014) to provide differentiation between the different stages of the clouds detected by the vertically pointing radar, and subsequently analysis of the role of turbulence on cloud evolution.

Acknowledgments. The authors thank three anonymous reviewers for their helpful comments and suggestions, which resulted in the improvement of a previous version of the manuscript. This research was supported in part under Contract DE-SC00112704 to Brookhaven National Laboratory by the Atmospheric System Research program of the Office of Biological and Environmental Research of the U.S. Department of Energy. Data used here were obtained from the ARM data archive (http://www.archive.arm.gov).

\section{REFERENCES}

Albrecht, B. A., 1989: Aerosols, cloud microphysics, and fractional cloudiness. Science, 245, 1227-1230, https://doi.org/10.1126/ science.245.4923.1227.

Austin, P., Y. Wang, R. Pincus, and V. Kujala, 1995: Precipitation in stratocumulus clouds: Observations and modelling results.
J. Atmos. Sci., 52, 2329-2352, https://doi.org/10.1175/15200469(1995)052<2329:PISCOA>2.0.CO;2.

Ayala, O., B. Rosa, and L. P. Wang, 2008: Effects of turbulence on the geometric collision rate of sedimenting droplets. Part 2. Theory and parameterization. New J. Phys., 10, 075016, https:// doi.org/10.1088/1367-2630/10/7/075016.

Baker, M. B., 1993: Variability in concentration of cloud condensation nuclei in the marine cloud-topped boundary layer. Tellus, 45B, 458-472, https://doi.org/10.3402/tellusb.v45i5.15742.

Borque, P., P. Kollias, and S. Giangrande, 2014: First observations of tracking clouds using scanning ARM cloud radars. J. Appl. Meteor. Climatol., 53, 2732-2746, https://doi.org/10.1175/JAMC-D13-0182.1.

— E. Luke, and P. Kollias, 2016: On the unified estimation of turbulence eddy dissipation rate using Doppler cloud radars and lidars. J. Geophys. Res. Atmos., 121, 5972-5989, https:// doi.org/10.1002/2015JD024543.

Brenguier, J.-L., and R. Wood, 2009: Observational strategies from the micro- to mesoscale. Clouds in the Perturbed Climate System: Their Relationship to Energy Balance, Atmospheric Dynamics, and Precipitation, J. Heintzenberg and R. J. Charlson, Eds., Strüngmann Forum Reports, Vol. 2, MIT Press, 487-510, https://doi.org/10.7551/mitpress/9780262012874.003.0021.

Chandrakar, K. K., W. Cantrell, K. Chang, D. Ciochetto, D. Niedermeier, M. Ovchinnikov, R. A. Shaw, and F. Yang, 2016: Aerosol indirect effect from turbulence-induced broadening of cloud-droplet size distributions. Proc. Natl. Acad. Sci. USA, 113, 14243-14248, https://doi.org/10.1073/pnas.1612686113.

Comstock, K. K., R. Wood, S. E. Yuter, and C. S. Bretherton, 2004: Reflectivity and rain rate in and below drizzling stratocumulus. Quart. J. Roy. Meteor. Soc., 130, 2891-2919, https://doi.org/ 10.1256/qj.03.187.

Cooper, W. A., 1989: Effects of variable droplet growth histories on droplet size distributions. Part I: Theory. J. Atmos. Sci., 46, 1301-1311, https://doi.org/10.1175/1520-0469(1989)046<1301: $\mathrm{EOVDGH}>2.0 . \mathrm{CO} ; 2$.

Delobbe, L., and H. Gallée, 1998: Simulation of marine stratocumulus: Effect of precipitation parameterization and sensitivity to droplet number concentration. Bound.-Layer Meteor., 89, 75-107, https://doi.org/10.1023/A:1001732526989.

Eaton, J. K., and J. R. Fessler, 1994: Preferential concentration of particles by turbulence. Int. J. Multiphase Flow, 20, 169-209, https://doi.org/10.1016/0301-9322(94)90072-8.

Feingold, G., and H. Siebert, 2009: Cloud-aerosol interactions from the micro to the cloud scale. Clouds in the Perturbed Climate System: Their Relationship to Energy Balance, Atmospheric Dynamics, and Precipitation, J. Heintzenberg and R. J. Charlson, Eds., Strüngmann Forum Reports, Vol. 2, MIT Press, 319-338.

— A. S. Frisch, B. Stevens, and W. R. Cotton, 1999: On the relationship among cloud turbulence, droplet formation and drizzle as viewed by Doppler radar, microwave radiometer and lidar. J. Geophys. Res., 104, 22 195-22 203, https://doi.org/ 10.1029/1999JD900482.

- A. McComiskey, D. Rosenfeld, and A. Sorooshian, 2013: On the relationship between cloud contact time and precipitation susceptibility to aerosol. J. Geophys. Res. Atmos., 118, 10544 10 554, https://doi.org/10.1002/jgrd.50819.

Franklin, C. N., P. A. Vaillancourt, and M. K. Yau, 2007: Statistics and parameterizations of the effect of turbulence on the geometric collision kernel of cloud droplets. J. Atmos. Sci., 64, 938-954, https://doi.org/10.1175/JAS3872.1.

Gaustad, K., and L. Riihimaki, 1996: Microwave radiometer retrievals (MWRRET) of cloud liquid water and precipitable 
water vapor. ARM Data Center, accessed 1 March 2016, https://doi.org/10.5439/1285691.

Grabowski, W. W., P. Dziekan, and H. Pawlowska, 2018: Lagrangian condensation microphysics with Twomey CCN activation. Geosci. Model Dev., 11, 103-120, https://doi.org/10.5194/ gmd-11-103-2018.

Hageman, D., and Coauthors, 1996: Aerosol Observing System (AOS): Aerosol data, 1-min, mentor-QC applied. ARM Data Center, accessed 1 March 2016, https://doi.org/10.5439/ 1025259.

Hardin, J., D. Nelson, Iosif, B. Isom, K. Johnson, A. Matthews, and N. Bharadwaj, 1990: W-band (95 GHz) ARM Cloud Radar. ARM Data Center, accessed 1 March 2016, https://doi.org/ $10.5439 / 1025317$.

Hudson, J. G., and S. Noble, 2014: CCN and vertical velocity influences on droplet concentrations and supersaturations in clean and polluted stratus clouds. J. Atmos. Sci., 71, 312-331, https://doi.org/10.1175/JAS-D-13-086.1.

Jung, E., B. A. Albrecht, A. Sorooshian, P. Zuidema, and H. H. Jonsson, 2016: Precipitation susceptibility in marine stratocumulus and shallow cumulus from airborne measurements. Atmos. Chem. Phys., 16, 11395-11413, https://doi.org/ 10.5194/acp-16-11395-2016.

Khain, A., M. Ovtchinnikov, M. Pinsky, A. Pokrovsky, and H. Krugliak, 2000: Notes on the state-of-the-art numerical modeling of cloud microphysics. Atmos. Res., 55, 159-224, https://doi.org/10.1016/S0169-8095(00)00064-8.

— M. Pinsky, T. Elperin, N. Kleeorin, I. Rogachevskii, and A. Kostinski, 2007: Critical comments to results of investigations of drop collisions in turbulent clouds. Atmos. Res., 86, 1-20, https://doi.org/10.1016/j.atmosres.2007.05.003.

Khvorostyanov, V. I., and J. A. Curry, 1999: A simple analytical model of aerosol properties with account for hygroscopic growth: 1. Equilibrium size spectra and cloud condensation nuclei activity spectra. J. Geophys. Res., 104, 2175-2184, https://doi.org/10.1029/98JD02673.

Kollias, P., and Coauthors, 2014: Scanning ARM cloud radars. Part II: Data quality control and processing. J. Atmos. Oceanic Technol., 31, 583-598, https://doi.org/10.1175/JTECH-D-13-00045.1.

Kolmogorov, A. N., 1941: Dissipation of energy in locally isotropic turbulence. Dokl. Akad. Nauk SSSR, 32, 16-18.

Korolev, A., M. Pinsky, and A. Khain, 2013: A new mechanism of droplet size distribution broadening during diffusional growth. J. Atmos. Sci., 70, 2051-2071, https://doi.org/10.1175/ JAS-D-12-0182.1.

Liu, Y., P. H. Daum, and S. S. Yum, 2006: Analytical expression for the relative dispersion of the cloud droplet size distribution. Geophys. Res. Lett., 33, L02810, https://doi.org/10.1029/2005GL024052.

Mann, J. A. L., J. C. Chiu, R. J. Hogan, E. J. O'Connor, T. S. L'Ecuyer, T. H. M. Stein, and A. Jefferson, 2014: Aerosol impacts on drizzle properties in warm clouds from ARM Mobile Facility maritime and continental deployments. J. Geophys. Res. Atmos., 119, 41364148, https://doi.org/10.1002/2013JD021339.

Martin, G. M., D. W. Johnson, and A. Spice, 1994: The measurement and parameterization of effective radius of droplets in warm stratocumulus clouds. J. Atmos. Sci., 51, 1823-1842, https:// doi.org/10.1175/1520-0469(1994)051<1823:TMAPOE>2.0.CO;2.

Mather, J. H., and J. W. Voyles, 2013: The ARM Climate Research Facility: A review of structure and capabilities. Bull. Amer. Meteor. Soc., 94, 377-392, https://doi.org/10.1175/BAMS-D-11-00218.1.
Nicholls, S., 1987: A model of drizzle growth in warm, turbulent, stratiform clouds. Quart. J. Roy. Meteor. Soc., 113, 1141-1170, https://doi.org/10.1002/qj.49711347805.

O’Connor, E. J., R. J. Hogan, and A. J. Illingworth, 2005: Retrieving stratocumulus drizzle parameters using Doppler radar and lidar. J. Appl. Meteor., 44, 14-27, https://doi.org/10.1175/ JAM-2181.1.

Pawlowska, H., and J.-L. Brenguier, 2003: An observational study of drizzle formation in stratocumulus clouds for general circulation model (GCM) parameterizations. J. Geophys. Res., 108, 8630, https://doi.org/10.1029/2002JD002679.

Pinsky, M. B., A. P. Khain, B. Grits, and M. Shapiro, 2006: Collisions of small drops in a turbulent flow. Part III: Relative droplet fluxes and swept volumes. J. Atmos. Sci., 63, 21232139, https://doi.org/10.1175/JAS3730.1.

,-- , and H. Krugliak, 2008: Collisions of cloud droplets in a turbulent flow. Part V: Application of detailed tables of turbulent collision rate enhancement to simulation of droplet spectra evolution. J. Atmos. Sci., 65, 357-374, https://doi.org/ 10.1175/2007JAS2358.1.

Pruppacher, H. R., and J. D. Klett, 2010: Microphysics of Clouds and Precipitation. L. A. Atmospheric and Oceanographic Sciences Library, Vol. 18, Springer, 954 pp., https://doi.org/ 10.1007/978-0-306-48100-0.

Roberts, G., and A. Nenes, 2005: A continuous-flow streamwise thermal-gradient $\mathrm{CCN}$ chamber for atmospheric measurements. Aerosol Sci. Technol., 39, 206-221, https://doi.org/10.1080/ 027868290913988.

Terai, C. R., R. Wood, D. C. Leon, and P. Zuidema, 2012: Does precipitation susceptibility vary with increasing cloud thickness in marine stratocumulus? Atmos. Chem. Phys., 12, 45674583, https://doi.org/10.5194/acp-12-4567-2012.

Vaillancourt, P. A., M. K. Yau, P. Bartello, and W. W. Grabowski, 2002: Microscopic approach to cloud droplet growth by condensation. Part II: Turbulence, clustering, and condensational growth. J. Atmos. Sci., 59, 3421-3435, https://doi.org/10.1175/ 1520-0469(2002)059<3421:MATCDG >2.0.CO;2.

van Zanten, M. C., B. Stevens, G. Vali, and D. Lenschow, 2005: Observations of drizzle in nocturnal marine stratocumulus. J. Atmos. Sci., 62, 88-106, https://doi.org/10.1175/JAS-3355.1.

Wang, L.-P., O. Ayala, B. Rosa, and W. W. Grabowski, 2008: Turbulent collision efficiency of heavy particles relevant to cloud droplets. New J. Phys., 10, 075013, https://doi.org/10.1088/1367-2630/10/ 7/075013.

Wood, R., 2005: Drizzle in stratiform boundary layer clouds. Part I: Vertical and horizontal structure. J. Atmos. Sci., 62, 30113033, https://doi.org/10.1175/JAS3529.1.

_ , and Coauthors, 2015: Clouds, aerosols, and precipitation in the marine boundary layer: An ARM Mobile Facility deployment. Bull. Amer. Meteor. Soc., 96, 419-440, https:// doi.org/10.1175/BAMS-D-13-00180.1.

Wulfmeyer, V., and Coauthors, 2008: The convective and orographically induced precipitation study: A research and development project of the World Weather Research Program for improving quantitative precipitation forecasting in lowmountain regions. Bull. Amer. Meteor. Soc., 89, 1477-1486, https://doi.org/10.1175/1520-0477-89.10.1469.

Yang, F., R. Shaw, and H. Xue, 2016: Conditions for superadiabatic droplet growth after entrainment mixing. Atmos. Chem. Phys., 16, 9421-9433, https://doi.org/10.5194/acp-16-9421-2016. 